epilepticus. Curarisation of the patient, although it stops the convulsions, does not arrest seizure activity in the brain, and so oedema and hypoxia develop further, producing possibly permanent brain damage. The long-term use of an anaesthetic gas, such as halothane, is unsuitable because of its general toxicity. Besides their anticonvulsive properties the barbiturates have been shown to protect the brain against anoxia and ischaemia and to lower the increased intracranial pressure. ${ }^{5}$ Barbiturate coma has recently been successfully used to treat both severe traumatic brain damage and Reye's syndrome. ${ }^{5}$

The treatment of intractable status epilepticus by general anaesthesia requires an intensive care unit with equipment for controlled ventilation and continuous monitoring of arterial pressure and cerebral function. Although the cerebral function monitor only partially reflects the pattern of electrical activity of the brain seen on an electroencephalogram, it provides an adequate record of the epileptic discharges, a particularly useful feature being its ability to show the events of several days on a short strip of paper. Follow-up of the neurological status of the patient by mere physical examination is not possible during general anaesthesia. This underlines the importance of adequate diagnostic examinations, including computed tomography.

${ }^{1}$ Browne TR. Drug therapy of status epilepticus. $\mathcal{F}$ Maine Med Ass 1978; 69:199-207.

2 Brown AS, Horton JM. Status epilepticus treated by intravenous infusions of thiopentone sodium. Br Med $\mathcal{F} 1967 ; \mathrm{i}: 27-8$.

${ }^{3}$ Bladin PF, Vajda FJ, Symington GR. Therapeutic problems related to tonic status epilepticus. Clin Exp Neurol 1977;14:203-7.

4 Prior P. Monitoring cerebral function. Long-term recordings of cerebral electrical activity. Amsterdam: Elsevier-North-Holland, 1979.

${ }^{5}$ Miller JD. Barbiturates and raised intracranial pressure. Ann Neurol $1979 ; 6: 189-93$.

(Accepted 14 November 1980)

Department of Neurology, University of Helsinki, SF-00290 Helsinki 29, Finland

MARKKU PARTINEN, MD, resident in neurology

JUSSI KOVANEN, MD, lecturer in neurology

Department of Anaesthesiology, University of Helsinki, Helsinki, Finland

EIJA NILSSON, MD, lecturer in anaesthesiology

\section{Child abuse presenting as apparent "near-miss" sudden infant death syndrome}

"Near-miss" sudden infant death syndrome refers to infants previously well who, during sleep, experience an episode of apnoea, limpness, and cyanosis or pallor that is terminated by vigorous stimulation or mouth-to-mouth resuscitation. ${ }^{1}$ Several conditions such as sepsis, fits, aspiration, and oesophageal reflux may present a similar clinical picture and are excluded by appropriate investigations.

Two cases of child abuse simulating near-miss sudden infant death syndrome have been described. ${ }^{2}$ In each case the mother had deliberately attempted to arrest respiration in hospital after admission to investigate recurrent apnoeic episodes. I describe a further case of this form of child abuse.

\section{Case report}

A 4-month-old boy was brought to hospital by his mother after an apnoeic episode at home. The history obtained was that, having found the baby apnoeic and cyanosed in his cot, his mother had resuscitated him by shaking him and slapping his face. The baby had previously been well. He had been born at 32 weeks' gestation and developed severe respiratory distress syndrome necessitating transfer to another hospital for ventilation. He was allowed home to his mother aged 32 days. His mother (aged 27 years) had bronchiectasis, which had necessitated her staying in hospital from the fifteenth week of pregnancy until delivery. She had suffered from depression with suicidal thoughts, but had no psychiatric history. On the day before the baby's admission his father had been admitted to hospital with haematemesis.

On admission the infant was pale and hypothermic but centrally pink. $\mathrm{He}$ was conscious but irritable with a generalised increase in muscle tone. His fundi were normal and there was no evidence of increased intracranial pressure. Respiratory system, cardiovascular system, and abdomen were normal. A small faint bruise was noted above his upper lip, which his mother attributed to her attempts at resuscitation. He otherwise appeared well cared for.

Investigations showed a metabolic acidosis $\left(\mathrm{pH} 7.24, \mathrm{PaCO}_{2} 3.1 \mathrm{kPa}\right.$ $(23 \mathrm{~mm} \mathrm{Hg})$, bicarbonate $10 \mathrm{mmol}(\mathrm{mEq}) / 1)$ but normal serum urea, electrolyte, calcium, and blood glucose concentrations. Haemoglobin concentration was $9.6 \mathrm{~g} / \mathrm{dl}$ and white cell count $28.5 \times 10^{9} / 1$ (34 \% neutrophils, $58 \%$ lymphocytes, $3 \%$ monocytes, and $4 \%$ eosinophils). No bacterial or viral pathogens were isolated from cultures of blood, urine, cerebrospinal fluid, faeces, and throat swabs. Chest $x$-ray films and skeletal survey were normal.

The baby was managed by gradual warming and intravenous antibiotics. Four hours later body temperature, colour, and muscle tone were normal and he took a bottle feed. Five days later he developed fever and a macular rash that persisted for two days, but recovery was otherwise uneventful. One week after his admission his mother was admitted to hospital after taking an overdose of diazepam. On recovery she was referred for psychiatric evaluation. She confessed that she had deliberately attempted to arrest the baby's respiration by holding his nose but had become frightened when he became cyanosed and apnoeic. The infant is at present placed with relatives.

\section{Comment}

This case and the two previously described ${ }^{2}$ indicate that child abuse should be considered in the differential diagnosis of near-miss sudden infant death syndrome. In our case abuse occurred against a background of maternal depression related to prolonged hospital admission, early separation from the baby, and acute paternal illness. Thus adequate background information should be obtained in cases of apparent near-miss sudden infant death syndrome. This should include details of maternal psychiatric illness, marital or family stress, and any contact with a social worker. Data should be obtained as indirectly as possible so as not to exacerbate feelings of anxiety and guilt that will already be present in the parents. During physical examination careful inspection of the nose and mouth should be made for pinch marks, bruising, or trauma to the gums.

Appropriate management might entail home monitoring and instruction in resuscitation in the case of genuine near-miss sudden infant death syndrome ${ }^{3}$ whereas an infant already subjected to child abuse would clearly be at risk if discharged to the same home environment.

I thank Dr D Haigh for permission to report this case under his care.

${ }^{1}$ Kelly DH, Shannon DC. Periodic breathing in infants with near-miss sudden infant death syndrome. Pediatrics 1979;63:355-9.

2 Berger D. Child abuse simulating "near miss" sudden infant death syndrome. F Pediatrics 1979;95:554-6.

${ }^{3}$ Kelly DH, Shannon DC, O'Connell K. Care of infants with near-miss sudden infant death syndrome. Pediatrics 1978;61:511-4.

(Accepted 19 November 1980)

Bradford Children's Hospital, Bradford BD8 7QF

A M B MINFORD, MRCP, DCH, senior registrar in paediatrics

\section{Are population-genetic mechanisms responsible for clustering of cases of Creutzfeldt-Jakob disease?}

There is considerable indirect evidence that susceptibility to Creutzfeldt-Jakob disease may be genetically determined, ${ }^{1}$ though the exact mechanism is still not clear. About $15 \%$ of patients with the disease are familial cases. ${ }^{1}$ An increased incidence of the disease has been reported in some areas, with spatiotemporal clusterings in England ${ }^{2}$ and Czechoslovakia. ${ }^{3}$ A genetic hypothesis may be advanced for at least some of these observations: in familial Creutzfeldt-Jakob disease genes controlling susceptibility to the disease are shared with relatives, and the agent may be acquired by contact or vertical transmission or perhaps aciivated by genetically determined mechanisms. The frequency of genes or genotypes contributing to the disease may in some populations be increased by drift, founder effect, or inbreeding.

In 1976 we observed a clustering of cases of Creutzfeldt-Jakob disease in a rural district of south-east Slovakia. The high incidence of such a rare disease seemed unlikely to be coincidental so we studied the genetic structure of the area. Genetic isolates have 
persisted in many regions of Slovakia up to the middle of the century, and long-term isolation might have increased the frequency of the hypothetical gene(s) controlling susceptibility to Creutzfeldt-Jakob disease.

\section{Cases and investigations}

From August 1972 to February 1980 four cases of Creutzfeldt-Jakob disease occurred in neighbouring localities, two of them in one village. A review of hospital files in the neighbouring district and adjacent region of Hungary disclosed a further four definite and one probable case that had occurred in the same period. In the eight definite cases the patients had rapidly progressing dementia with severe neurological disturbances and the disease was diagnosed on the basis of light microscopy findings of unequivocal spongiosis, astrocytosis, and neuronal loss (Dr Eva Mitrová, Research Institute of Preventive Medicine, Bratislava). The ninth patient had a characteristic electroencephalogram but necropsy was performed late and the changes were not entirely diagnostic of Creutzfeldt-Jakob disease. The Slovak patients all came from families that had lived in the area for many generations.

Three indices of genetic structure in the population were investigated: the endogamy $v$ exogamy rate, the mean marital distance, and the inbreeding coefficient. The first two indices were examined in five villages, including those where the patients came from, whereas the last was determined only in the village where two patients were discovered. The parish records covered $200-250$ years.

The endogamy rate, measured by the frequency of village-endogamous matings, was lower in the investigated area than in the mountainous regions of northern Slovakia, so that the villages could not be considered endogamous genetic isolates. The mean marital distance, however, was extremely low during the investigated period, except for the last two to three decades, when it increased rapidly. Its value never exceeded $10 \mathrm{~km}$ and was usually much smaller. In all villages exogamous matings were contracted with spouses from neighbouring and adjacent villages, and practically all marriages were region-endogamous. Only during and after the second world war did the exogamy rate and the mean marital distance begin to increase rapidly.

The population structure in the investigated area before the recent changes fitted Wright's model ${ }^{4}$ of "isolation by distance." The genetic consequences of this model are an increase of the population inbreeding coefficient and the drift phenomena. The inbreeding coefficient was estimated by the method of isonymy, which uses the frequency of matings between people with identical surnames. This method is particularly convenient for use in the Slovak population, where surnames tend to be specific to both the family and the village.

The value of the coefficient of inbreeding in the investigated village increased steadily during the nineteenth century from $F=0.006$ to a maximum of $\mathrm{F}=0.012$ at the end of the nineteenth and beginning of the twentieth centuries and dropped subsequently to its present value of $F=$ 0.001 .

\section{Comment}

The value of $\mathrm{F}=0.012$ that the inbreeding coefficient reached at the beginning of this century is the highest value found in a Slovak community and is in the highest range of $F$ values reported from any European population. This indicates that the population of the area we studied has been inbred and isolated, in spite of its comparatively high exogamy rate.

From these results we concluded that the population structure in this district of Slovakia would have allowed genetic drift and related mechanisms to operate. Thus these mechanisms might have produced local increase in frequencies of the postulated gene(s) or genotype controlling susceptibility to Creutzfeldt-Jakob disease.

An alternative hypothesis of episodic common exposure to the agent, experienced by unrelated persons and leading to the appearance of clustering, cannot be completely rejected, however, since the epidemiology of Creutzfeldt-Jakob disease is still obscure. Nevertheless, the available data do not provide any evidence in its favour. No contacts among the nine patients have been proved, and, according to their relatives, they did not know each other and no ascertainable familial relation existed between them.

The importance of the scrapie virus is difficult to assess. Nevertheless, scrapie has never been reported from this region of Slovakia, and the last histopathologically proved case of scrapie in sheep in the territory of Slovakia was reported in 1877, in sheep imported from Spain. ${ }^{5}$

If the hypothesis that population-genetic mechanisms participated in increasing the incidence of Creutzfeldt-Jakob disease in the area studied proves correct, it may be of predictive value. Genetic isolates have vanished rapidly with the socioeconomic changes that have taken place in Slovakia in recent decades. As a consequence the population as a whole is approaching genetic homogeneity, and local irregularities of genetic composition brought about by drift, foreign immigration, and inbreeding are bound to disappear. Accordingly, a fall in the incidence of Creutzfeldt-Jakob disease may be expected in the investigated area in succeeding generations.

We thank Drs T Lehotsky, J Rattaj, and I Messerschmidt for their co-operation. Special thanks are due to Dr Eva Mitrová for bringing to our attention the report by Zlamal.

1 Masters CL, Harris LO, Gajdusek CD, Gibbs CJ Jr, Bernoulli C, Asher DM. Creutzfeldt-Jakob disease: patterns of worldwide occurrence and the significance of familial and sporadic clustering. Ann Neurol $1979 ; 5: 177-88$.

${ }^{2}$ Matthews WB. Epidemiology of Creutzfeldt-Jakob disease in England and Wales. $\mathcal{F}$ Neurol Neurosurg Psychiatry 1975;38:210-3.

${ }^{3}$ Mayer V, Mitrová E, Orolin D. Creutzfeldt-Jakob disease in Czechoslovakia and a working concept of its surveillance. In: Prusiner SB, Hadlow WJ, eds. Slow transmissible diseases of the nervous system. Vol I. New York: Academic Press, 1979:287-303.

${ }^{4}$ Wright $S$. Isolation by distance. Genetics $1943 ; 28: 114-38$.

${ }^{5}$ Zlamal V. Comprehensive clinicopathological review of animal diseases. Budapest: Magyar Tudom Irod, 1877. (In Hungarian.)

(Accepted 4 November 1980)

Department of Anthropology, Comenius University, Bratislava

V FERÁ, PHD

Z KROUPOVÁ, PHD

Institute of Virology, Slovak Academy of Sciences, Bratislava V MAYER, MD

\section{Chlorpropamide-alcohol flushing and proteinuria in non-insulin- dependent diabetics}

Some patients with non-insulin-dependent diabetes show facial flushing after drinking alcohol when taking chlorpropamide (chlorpropamide-alcohol flushing). ${ }^{2}$ We reported that non-insulindependent diabetics who show this reaction have a decreased frequency of retinopathy when compared with those who do not. ${ }^{3}$ We investigated whether the same was true for diabetic nephropathy.

\section{Patients, methods, and results}

We examined 291 non-insulin-dependent diabetics from the patients attending our clinic. Selection was random, but we tried to study as many as possible with diabetes of more than 15 years' duration. Most were already taking chlorpropamide; the others were tested as previously described. ${ }^{3}$

Nephropathy was diagnosed if proteinuria was found on testing with reagent strips (Albustix) on at least three consecutive clinic visits in the absence of other causes of proteinuria. Renal biopsy was not performed. Of the 291 patients, 191 were positive and 100 negative for chlorpropamide-alcohol flushing. The mean ages at diagnosis ( 48 and 52 years respectively) and durations of diabetes (mean $\pm S E M \quad 11 \cdot 7 \pm 0 \cdot 6$ and $9 \cdot 4 \pm 0 \cdot 7$ years) were similar in the two groups. The results were analysed by $\chi^{2}$ testing.

Persistent proteinuria was seen more commonly in patients who were negative for chlorpropamide-alcohol flushing $(14 / 100 ; 14 \%)$ than in those who were positive $(4 / 191 ; 2 \%)(p<0.001)$. The mean ages $(50$ and 49 years respectively) and durations of diabetes $(8 \cdot 0+1 \cdot 1$ years and $6 \cdot 5 \pm 0.9)$ when proteinuria first appeared were similar in the two groups. Nine of the patients in the group negative for flushing and one in the positive group had evidence of impaired renal function (urea $>7.5 \mathrm{mmol} / 1(45 \mathrm{mg} / 100 \mathrm{ml}$ ), or creatinine $>110 \mathrm{mmol} / 1(1243 \mathrm{mg} / 100 \mathrm{ml}))$. Twelve of the 14 patients who did not flush but had proteinuria also had diabetic retinopathy (two maculopathy and eight proliferative retinopathy); only one of the four patients positive for flushing had any retinopathy.

\section{Comment}

These results suggest that chlorpropamide-alcohol flushing is associated with a relative freedom from nephropathy (as shown by persistent proteinuria) as is the case with retinopathy. ${ }^{3}$ This is perhaps hardly surprising since nephropathy is often found with retinopathy and represents a similar pathological process. If, as we think, chlorpropamide-alcohol flushing is an inherited trait ${ }^{2}$ the tendency to develop nephropathy must also be, in part, inherited. 